\section{Persistent haemorrhagic ascites in generalised haemolymphangiomatosis: a therapeutic dilemma}

We report a case of intractable, recurrent intraperitoneal bleeding secondary to visceral lymphangiomatosis, which we do not think has been reported before.

\section{Case report}

A woman was well until 1976, when, aged 24 , she developed recurrent haemoptyses. Chest radiography showed multiple right cavities in the uppe zone. Sputum screening for acid fast tubercle bacilli yielded negative results, and bronchoscopy was unhelpful. Right upper lobectomy was performed, and histological examination showed fibrous cavities lined with alveolar macrophages laden with pigment.

She presented in 1981 with massive splenomegaly. Haemoglobin concentration was $121 \mathrm{~g} / \mathrm{l}$, and a peripheral blood film showed macrocytosis and Howell-Jolly bodies. The histological appearance of a bone marrow trephine biopsy specimen was typical of myelofibrosis. At laparotomy a multicystic spleen weighing $4 \cdot 2 \mathrm{~kg}$ was removed. The splenic pulp was replaced by large thin walled vascular space filled with proteinaceous material (figure). Postoperative chest radiography showed upper mediastinal widening, and a skeletal survey showed sclerotic deposits in the pelvis, scapulae, and femoral heads.

In 1983 she developed severe anaemia (haemoglobin concentration $55 \mathrm{~g} / \mathrm{l}$ ) and gross ascites. Aspiration showed heavily bloodstained fluid with an initia haemoglobin content of $77 \mathrm{~g} / \mathrm{l}$. Over the next three years she required abdominal paracentesis on several occasions and received 48 units of blood. In January 1985 a Levine shunt was inserted and drained via the right internal jugular vein; her ascites improved. Scanning after red blood cells had been labelled with technetium-99m showed an unusual vascular pattern in the inferolateral aspect of the liver. At repeat laparotomy the left hepatic lobe contained large bullas filled with blood, which were excised. The venous tip of the Levine shunt became
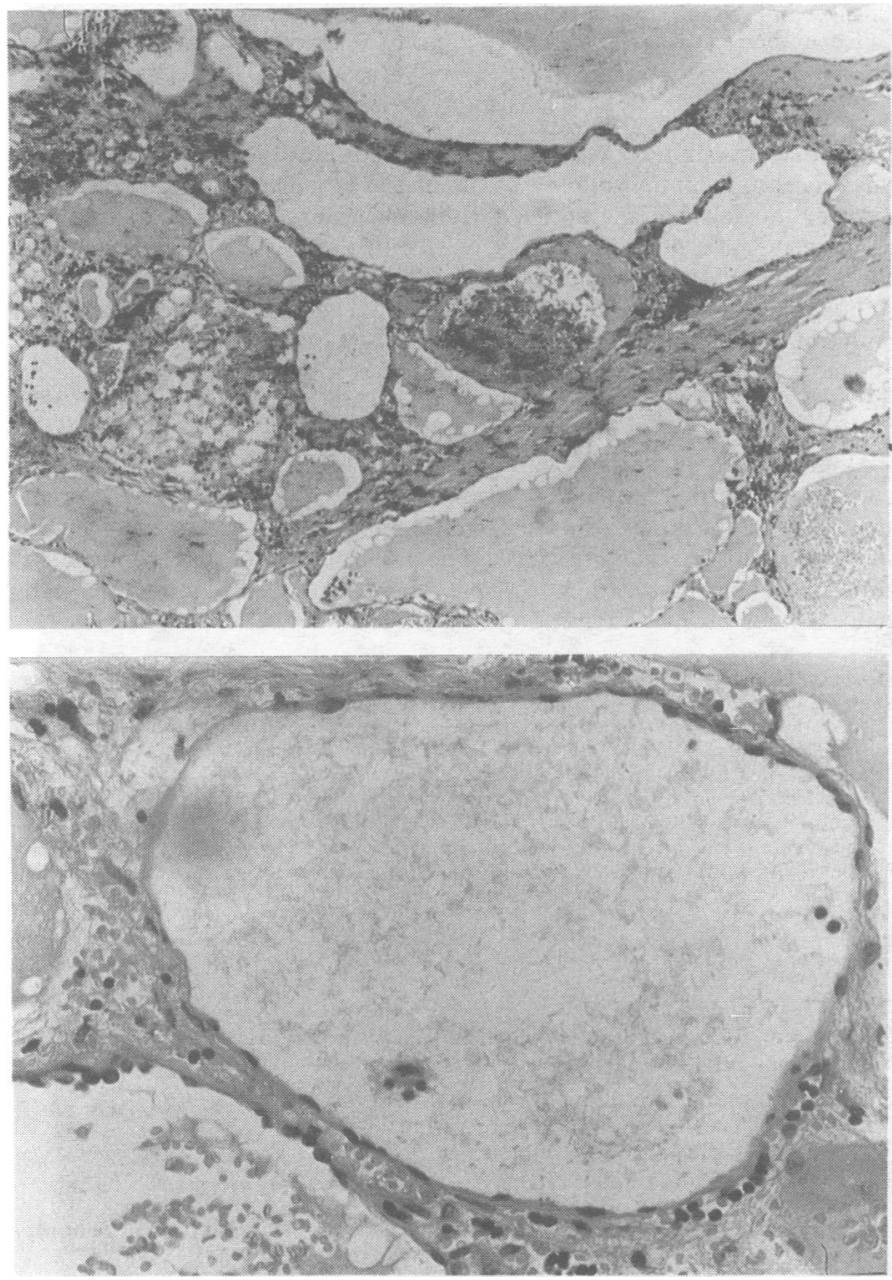

Histological appearance of spleen. Top (low power): Multicystic spaces filled with proteinaceous material and linked by low endothelium. Bottom (high power): Detail of endothelium lining cysts. obstructed in October 1985 and required replacement with a similar shunt to the left internal jugular vein. Subsequent scanning showed retrograde flow around this shunt but not down the superior vena cava. In February 1986, aged 34, she collapsed with angiographically proved emboli in both main pulmonary arteries. Streptokinase was thought to be contraindicated and embolectomy was unsuccessful. Necropsy showed organised thrombus extending through most of both pulmonary vascular trees as well as lymphangiomas of the liver, mediastinal pleura, kidneys, pancreas, and heart. The right atrium contained friable adherent clot $3 \mathrm{~cm}$ long.

\section{Comment}

Splenomegaly due to cystic lymphangiomatosis is rare. A review of reports between 1940 and 1952 identified 27 cases. ${ }^{1}$ Associated ascites is usually chylous and implies coexistent retroperitoneal lymphatic disease. Such ascites has been successfully treated with a Denver peritoneal venous shunt. ${ }^{2}$ Severe haemorrhagic ascites in a patient with normal coagulation has to our knowledge not been reported before.

The blood in the ascitic fluid may well have obstructed the first shunt in our patient. The second shunt was obstructed by a fibrous sheath. This complication is well recognised, ${ }^{3}$ and research into non-silicone materials that cause less fibroplasia is now in progress. Caval thrombi are a recognised and dangerous complication of Levine-shunts and require anticoagulation. Unfortunately, our patient's recurrent emboli were both silent and untreatable as long term treatment was contraindicated by continuing bleeding.

We thank Mr R Norton, Dr K Hollinrake, and Dr T Ashworth for their help with this case.

1 Fowler RH. Collective review: non-parasitic benign cystic tumors of the spleen. International Abstracts of Surgery 1953;96:209-27. (In Surg Gynecol Obstet 1953; March)

2 Jack HT, Chang J, Newkirk G, Carlton JD, Miller JD, Orsoni E. Generalised lymphangiomatosis with chylous ascites- treatment by peritoneovenous shunting. F Pediatr Surg 1980;15:748-50. 3 Leveen HH, Vujic I, D'Ovidio NG, Hutto RB. Peritoneovenous shunt occlusion: aetiology, diagnosis, therapy. Ann Surg 1984;200:212-8.

(Accepted 3 February 1987)

George Eliot Hospital, Nuneaton CV10 7DJ

BERNARD I SMITS, FRCP, consultant physician

E PULLICINO, MRCP, registrar in general medicine

ANNE NICOLSON, MRCP, senior registrar in general medicine

G A COURT, FRCs, consultant surgeon

\section{Strongyloides stercoralis infection in Burma Star veterans}

Infections with the nematode worm Strongyloides stercoralis may persist for many years after exposure, by autoinfection. The condition is well described among former second world war prisoners of the Japanese ${ }^{1}$ and occurs in over a fifth of those who worked on the infamous Thai-Burma railway. ${ }^{2}$ Most infections cause a "creeping eruption" or "larva currens" eruptior -- in itchy, serpiginous urticarial rash which occurs intermittently, usually over the trunk. The real danger of strongyloidiasis, however, is the potentially fatal hyperinfection syndrome, which may occur when infected subjects become immunosuppressed-particularly with corticosteroid drugs. ${ }^{3}$

Soldiers of the second world war Burma campaign fought in areas endemic for strongyloidiasis. They usually had reasonably adequate footwear, however, making them much less liable to infection (which is acquired by skin penetration of free living soil larvae). Nevertheless, we have recently described a case of strongyloides infection in a British Burma Star veteran, ${ }^{4}$ diagnosed 40 years after tropical exposure. We therefore attempted to determine the prevalence of strongyloidiasis among this group of men.

\section{Patients, methods, and results}

We circulated a questionnaire at two reunion meetings of the Burma Star Association in 1985 in Bridlington and London. These questionnaires asked whether members suffered a creeping eruption type of rash, which was described in detail (colour photographs of the rash were also distributed). Those who responded positively were contacted further by post, and if their rash was considered typical investigations were arranged (three stool samples for microscopy and larval culture, blood eosinophil count, and an enzyme linked immunosorbent assay (ELISA) serum test for strongyloides). Of 566 who replied to the questionnaire, three men were finally found to have strongyloidiasisprevalence of $0.53 \%$. These were all successfully treated with mebendazole. 


\section{Comment}

In ex-Far East prisoners of war $84 \%$ of those with strongyloidiasis have the typical rash. ' Given also the accepted limitations of our survey, this suggests estimate. Nevertheless, even this figure means that some 100 to 200 Burma veterans in Britain today have undiagnosed strongyloides infections. Although the infection rate in ex-Japanese prisoners is much higher, doctors should also be aware of the possibility of strongyloidiasis in veterans of the Burma campaign.

1 Gill GV, Bell DR. Strongyloides stercoralis infection in former Far East prisoners of war. Br Med $\mathfrak{f}$ 1979;ii:572-4.

2 Gill GV, Bell DR. Strongyloidiasis in ex prisoners of war in south east Asia. Br Med $\mathfrak{f}$ 1980;280:1319.

3 Cruz T, Reboucas G, Rocha H. Fatal strongyloidiasis in patients receiving corticosteroids. N Engl f Med 1966;275:1093-6.

4 Gill GV, Bell DR, Pearce RJ. Strongyloides stercoralis infection in a former soldier of the Burma campaign: 40 years later. $B r M e d \mathcal{F}$ 1986;292:882.

(Accepted 13 February 1987)

Department of Tropical Medicine and Infectious Diseases, Liverpool School of Tropical Medicine, Liverpool L3 $50 \mathrm{~A}$

GEOFFREY V GILL, MD, MRCP, honorary senior lecturer

DION R BELL, FRCP, DTM\&H, reader and honorary consultant physician

Correspondence to: Dr Bell. that the prevalence of $0.5 \%$ for Burma Star veterans is an under-

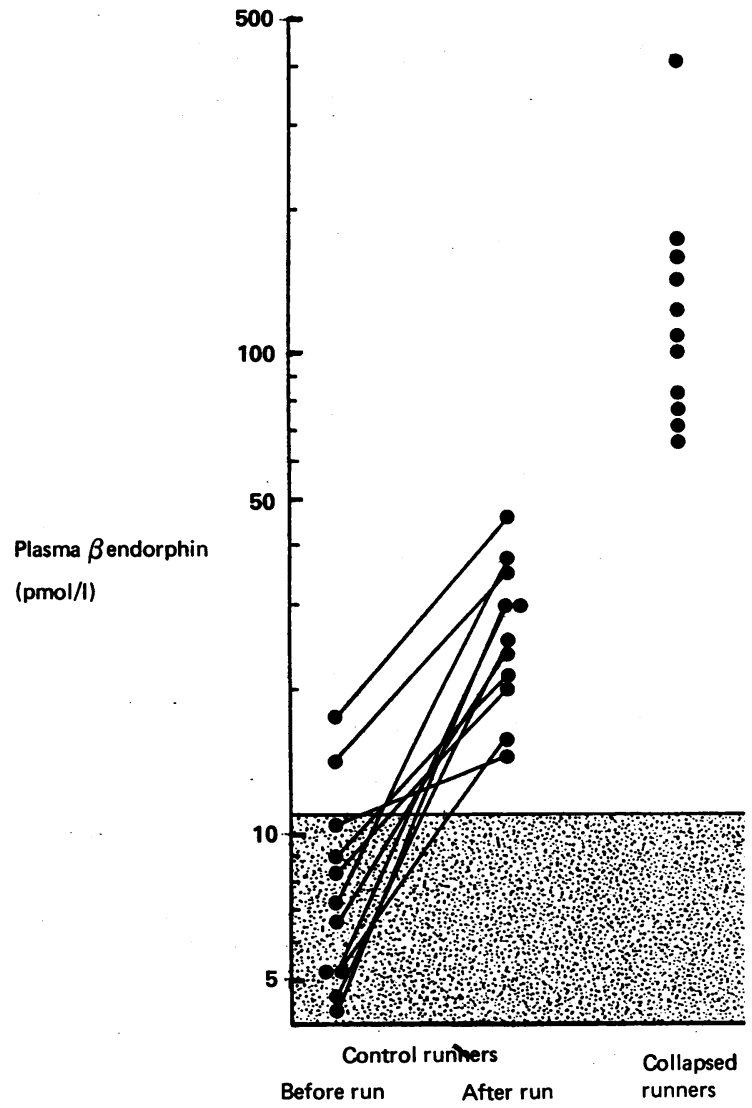

Changes in $\beta$ endorphin concentrations (log scale) in those who completed the half marathon and those who collapsed near the finish. 0 Normal reference range. they represent a very small proportion of the entry, which now exceeds 25000 a year, we find it surprising that healthy men can run until they become confused, dehydrated, hyperthermic, and hypophosphataemic without first experiencing intolerable discomfort. Because endogenous opioids suppress pain, have a possible role in temperature regulation, and may be responsible for "runner's high" ${ }^{3}$ the concentration of $\beta$ endorphin -one of the most potent of these peptides-is worth considering as an important factor facilitating collapse during such runs.

\section{Subjects, methods, and results}

Blood samples were obtained from 11 runners who collapsed near the end of two consecutive Great North Runs and from a control group at both the start and finish of the race. Fortuitously, there were also 11 controls. Both groups comprised men of modest but previously undistinguished performance. The collapsers were aged 19-43 (median 27) and the controls 27-45 (37).

The plasma was separated immediately and stored at $-20^{\circ} \mathrm{C}$. As soon as was practicable after each race duplicate assays of plasma $\beta$ endorphin were performed by radioimmunoassay, after immune affinity chromatography, using a method giving a cross reaction with $\beta$ lipotrophin of less than $5 \%$. The figure shows the results.

The control group had a mean $\beta$ endorphin concentration of $8 \cdot 4(4 \cdot 2) \mathrm{pmol} / 1$ before the run and $27 \cdot 2(9 \cdot 7) \mathrm{pmol} / \mathrm{l}(\mathrm{SD})$ after the run. Two runners showed slightly increased initial concentrations, perhaps as a result of exercise or anxiety before the race. The highest control concentration after the run was $46 \cdot 2 \mathrm{pmol} / 1$. The collapsed group at the finish had a median $\beta$ endorphin concentration of 110 $\mathrm{pmol} / \mathrm{l}$ (range 66-414 pmol/l). The concentrations in the controls after the run were significantly higher than the corresponding starting concentrations $(p<0.005$, Wilcoxon signed rank test) and were themselves considerably exceeded by the concentrations found in those who collapsed during or at the finish of the race ( $p<0 \cdot 001$; Mann-Whitney rank sum test).

\section{Comment}

Though we cannot know the $\beta$ endorphin concentrations of the runners before collapse, and they may reasonably be assumed to increase during the process of collapsing, the evidence from the control group is that the concentrations are already high before this happens. Janal et al showed in a double blind study that long distance runners experience hypoalgesia and "runner's high" and that these effects are associated with an increase in $\beta$ endorphin concentrations and are inhibited by naloxone. ${ }^{3}$ We suggest that the unusually high concentrations of $\beta$ endorphin in those who collapsed were probably responsible for the insensitivity to pain, enabling the runner to keep going. The sense of wellbeing produced by opioid peptides may be a factor that determines the competitor's enthusiasm for running. At times this seems to be extraordinary: of the men we studied, one had collapsed during a previous half marathon, and another, who spent considerable time in intensive care after his run, subsequently expressed the intention to continue participating in such events.

Treadmill exercise produces an increase in $\beta$ endorphin concentration in both trained and untrained subjects. ${ }^{4} 5$ Gambert $e t$ al found this to be much greater in men than in women. ${ }^{3}$ Perhaps this accounts for the fact that over the past six years all of the runners who collapsed at the end of the Great North Run have been men.

Doubtless the potential collapser is caught up in the group enthusiasm that surrounds the run and is subjected to the pressures of self esteem and perhaps the knowledge that considerable sums of money given in sponsorship for charities are at risk. The important factor that enables such entrants to run until they collapse, however, is probably the high concentration of circulating endogenous opioids.

1. Dale G, Fleetwood JA, Inkster JS, Sainsbury JRC. Profound hypophosphataemia in patients collapsing after a "fun run " BrMed I 1986;292:447-8.

2 De Meirleir K, Arentz T, Hollmann W, Vanhaelst $L$. The role of endogenous opiates in thermal regulation of the body during exercise. BrMed $\mathcal{F} 1985 ; 290: 739-40$. man following long-distance running: effects of naloxone. Pain 1984;19:13-25.

Farrell PA, Gates WK, Maksud MG, Morgan WP. Increases in plasma beta-endorphin/betalipotropin immunoreactivity after treadmill running in humans. $\mathcal{F}$ Appl Physiol 1982;52:1245-9.

5 Gambert SR, Garthwaite TL, Pontzer CH, et al. Running elevates plasma beta-endorphin immunoreactivity and ACTH in untrained human subjects. Proc Soc Exp Biol Med 1981;168: 1-4.

(Accepted 28 January 1987)

Department of Clinical Biochemistry, Newcastle General Hospital, Newcastle upon Tyne NE4 6BE

G DALE, MD, senior lecturer and consultant chemical pathologist

J A FLEETWOOD, PHD, top grade biochemist

ANN WEDDELL, BSC, senior biochemist

R D ELLIS, BSC, biochemist

Department of Surgery, University of Newcastle upon Tyne Medical School,

J R C SAINSBURY, FRCS, senior registrar

Correspondence to: Dr Dale.
3 Janal MN, Colt EWD, Clark WC, Glusman M. Pain sensitivity and plasma endocrine levels in Newcastle NE2 4HH 